\title{
The Incidence of Malaria in Human Population of Shergarh District Mardan Pakistan
}

\author{
Inayat Ullah, Sulaiman Shams, Ibrar Ullah, Hazrat Wali, Rishma, Mehwish Nawaz and Sahib Gul \\ Afridi* \\ Department of Biochemistry, Mardan KPK, Pakistan \\ *Corresponding author: Sahib Gul Afridi, Department of Biochemistry, Mardan KPK, Pakistan
}

\section{ARTICLE INFO}

Received: 幽 June 06, 2019

Published: 㓞 June 13, 2019

Citation: Inayat Ullah, Sulaiman Shams, Ibrar Ullah, Hazrat Wali, Rishma, Mehwish Nawaz, Sahib Gul Afridi. The Incidence of Malaria in Human Population of Shergarh District Mardan Pakistan. Biomed J Sci \& Tech Res 18(5)-2019. BJSTR. MS.ID.003210.

Keywords: Malaria; Microscopy; Mardan; P. vivax; Pakistan

\begin{abstract}
This study aimed at investigating the occurrence of malaria infection in human population of Shergarh district Mardan during August 2015 to July 2016. Sum of 2830 blood samples were collected from male $(n=1560)$ and female $(n=1270)$ febrile patients visiting Rural Health Center (RHC) Shergarh. All samples were subjected to microscopic analysis to determine the prevalence of plasmodium genotypes in the study area. Among 2830 studied samples 228 samples (8.056\%) were found to be positive for malaria including $122(53.50 \%)$ male and $106(46.49 \%)$ female positive subjects. All of the positive samples were detected with only plasmodium vivax infection. Age wise distribution of positive cases revealed the higher rate of infection as $122 / 228(53.07 \%)$ in group C (31-45 years) followed by group B (16-30 years) as 70/228 (30.70\%) and A group (4-15 years) as $37 / 228(16.22 \%)$. The highest rate of infection was recorded in September as 49/228 (21.49\%) followed by August, October and May as 32/228 (14.03\%), 31/228 $(13.59 \%)$ and $31 / 228(13.59 \%)$, respectively. While the lowest number of cases was found in January and February each as $1 / 228(0.43 \%)$ followed by March and July as $4 / 228(1.75 \%)$ and 5/228 (2.19\%), respectively. It was concluded that malaria is still a major problem in rural population of District Mardan especially in Shergarh region might be due to poor sewage system and improper irrigation system in the area. Effective and prompt measures should be taken to curb the malarial infection at local and nationwide level in Pakistan by the government and non-government organizations.
\end{abstract}

\section{Introduction}

Malaria being one of the most infectious diseases is caused by unicellular parasites belong to Plasmodium genus. There are five malaria causing species of this genus including Plasmodium vivax, plasmodium falciparum, plasmodium ovale, plasmodium malariae and plasmodium knowelsi [1,2]. These species show variation in their morphology and drug resistance pattern, geographic distribution and their mode of pathologic process [2]. In 2016, an estimated number of 216 million cases of malarial infection have occurred worldwide leading to an estimated 445,000 deaths [3]. P. falciparum is taken into account the foremost fatal among all species, and accounts for most of the deaths due to malaria infection worldwide [4]. This infection is transmitted by a bite of infected Anopheles, female mosquito specie that introduces the plasmodium in its secretion into human blood system and leading to a number of symptoms including headache and fever, and in severe cases leading to death [5]. The infection is often diagnosed by the microscopic examination of blood using blood films or with antigen-based fast diagnostic tests. Molecular techniques are employed to diagnose the infection; however, these molecular strategies are not widely used because of their quality and cost [6]. Malaria infection is widely occurred in 109 countries mostly located in the tropics and sub-tropics [7].

In Africa, Papua and Haiti, P. falciparum is the the predominant species, where as $P$. vivax infection is endemic in the regions of Central and South America, North Africa, Near East and Indian landmass [8]. In Asia, particularly in Pakistan and Afghanistan, malaria continues to be a major public health issue with current transmission of each P. falciparum and P. vivax $[9,10]$. Pakistan, India, Ethiopia and Dutch East Indies contribute the 81\% mortality due malaria infection [11]. Around 95 million people in Pakistan live in areas with high prevalence of malaria infection [12]. It was almost completely eradicated in sixties however the abrupt rise 
of malaria infection occurred in Seventies. Within the last 20 years, rise in malarial cases has been attributed to prolonged monsoon season and floods that affected twenty million individuals in over sixty districts [13]. P. vivax contributed $65 \%$ of cases while the remaining $35 \%$ cases were caused due to $P$. falciparum infection, in Pakistan. In spite of malaria control and vector management programs in Pakistan, 5 million new cases of malaria and a substantial number of deaths are reported. Approximately $37 \%$ of cases have been reported in the areas of Pakistan located near Afghanistan border and other neighbor countries [14]. This study was designed to report the incidence of malaria infection along with the distribution of prevalent plasmodium species in Shergarh; a rural area of district Mardan Pakistan.

\section{Study Area}

This study was carried out at Rural Health Center (RHC) Shergarh Mardan. Shergarh is one of the populated towns of Mardan is situated on the main highway between Mardan and Swat. It is about 15 kilometers from the Malakand Mountains to the north, 12 $\mathrm{km}$ from Lund Khwar and $27 \mathrm{~km}$ from Mardan to the south.

\section{Study Population}

Subjects for this cross-sectional study were the febrile patients attending Rural Health Center (RHC) hospital Shergarh, Mardan. Subjects were divided into three groups on the basis of their ages i.e. group A: 1-15 years, group B: 16-30 years and group C. 31-45 years. The study consisted of 2830 blood samples from 1560 male and 1270 female subjects aged 1-45 years during August 2015 to July 2016 inhabitants of Shergarh District Mardan Khyber Pakhtunkhwa Pakistan.

\section{Sample Collection}

Some necessary information was collected from subjects regarding sex, age, residence, parent's occupation, general health condition, past history of malarial infection, surrounding conditions of their home, and presence or absence of domestic animals. Blood samples were collected from subjects and labeled properly.

\section{Preparation of Thick and Thin Blood Smears}

Thick and thin smear were prepared on the same slide from the finger pricked blood samples of all subjects under study. Fixation of the thin smear was done with methyl alcohol. Blood films were stained with $10 \%$ Giemsa stain. The screening was done under microscope 100X objective with oil immersion. All slides were cross checked by senior microscopist in RHC (Shergarh) Mardan.

\section{Results}

During current study blood samples of 2830 subjects with fibril fever were investigated for malaria infection. Out of 2830 samples, 228 samples were found positive for malaria showing $8.05 \%$ incidence of malaria infection in the area. In positive samples, 122 (53.50\%) were found as males while106 (46.5\%) were females. The highest ratio of positive cases was observed in male subjects in age group C as 65(28.50\%) followed by age group B as 42 (18.42\%) and lowest in age group A as 15(6.57\%) (Figure 1). In female the highest ratio was reported in age group C that is $56(24.56 \%)$ followed by age group B as $28(12.28 \%)$ and lowest in age group A as 22(9.64\%) cases. Among the infection causing species, $P$. vivax species was found to be responsible for all the infections in the area reported in this study while no other species including P. falciparum has been founded (Table 1)(Figure 2). Month wise prevalence of plasmodium parasite was found the highest in September as 49 (21.49\%) while the lowest rate was found in months of January and February as only $1(0.43 \%)$ followed by month of March and July as 4 (1.75\%), and 5(2.19\%) respectively (Figure 3). Among the studied samples of 1270 female subjects, 106 were found positive. The mean prevalence of malaria was high in non-pregnant women as compared to pregnant women. In pregnant women the prevalence was very low that is $8(7.54 \%)$ while in non-pregnant it was recorded as 98 (92.45\%) infected subjects (Figure 4).

Table 1: Over all prevalence of plasmodium species.

\begin{tabular}{|c|c|c|c|c|c|c|c|c|}
\hline Months & \multicolumn{3}{|c|}{ Age Groups } & \multicolumn{2}{c|}{ Sex } & \multicolumn{2}{c|}{ No of Samples } & Total \\
\hline & A & B & C & M & F & +Ve & -Ve & \\
\hline AUG & 8 & 11 & 13 & 21 & 11 & 32 & 238 & 270 \\
\hline SEP & 1 & 21 & 27 & 22 & 27 & 49 & 341 & 390 \\
\hline OCT & 4 & 9 & 18 & 18 & 13 & 31 & 280 & 311 \\
\hline NOV & 0 & 4 & 15 & 13 & 6 & 19 & 276 & 295 \\
\hline DEC & 2 & 2 & 6 & 0 & 6 & 10 & 170 & 180 \\
\hline JAN & 0 & 0 & 1 & 0 & 1 & 1 & 171 & 172 \\
\hline FEB & 1 & 0 & 0 & 0 & 0 & 1 & 168 & 169 \\
\hline MAR & 1 & 1 & 2 & 0 & 3 & 4 & 172 & 176 \\
\hline APR & 5 & 7 & 5 & 0 & 11 & 17 & 217 & 234 \\
\hline MAY & 7 & 9 & 15 & 0 & 13 & 31 & 236 & 267 \\
\hline JUN & 7 & 5 & 16 & 0 & 12 & 28 & 241 & 269 \\
\hline JUL & 1 & 1 & 3 & 2 & 2 & 5 & 92 & 97 \\
\hline Total & 37 & 70 & 121 & 76 & 105 & 228 & 2602 & 2830 \\
\hline
\end{tabular}

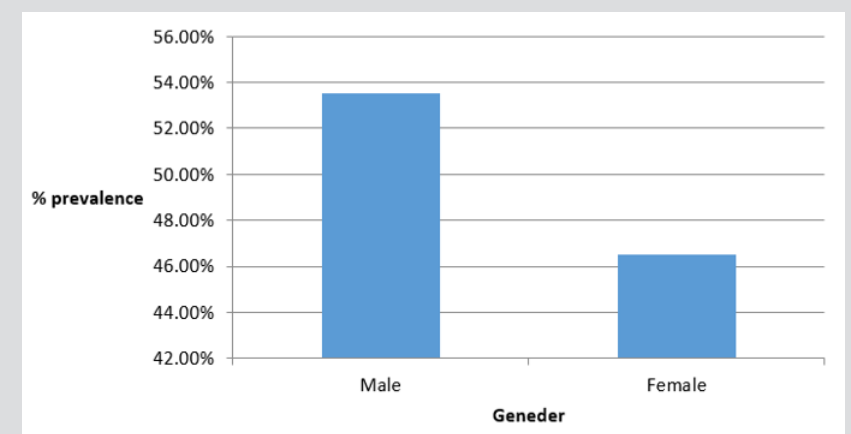

Figure 1: Gender wise prevalence of malaria in positive samples in RHC Shergarh Mardan. 


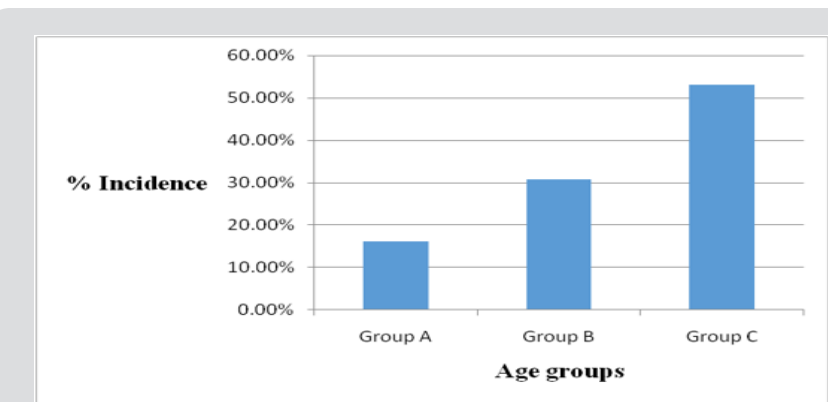

Figure 2: Age wise prevalence of malaria in Shergarh Mardan.

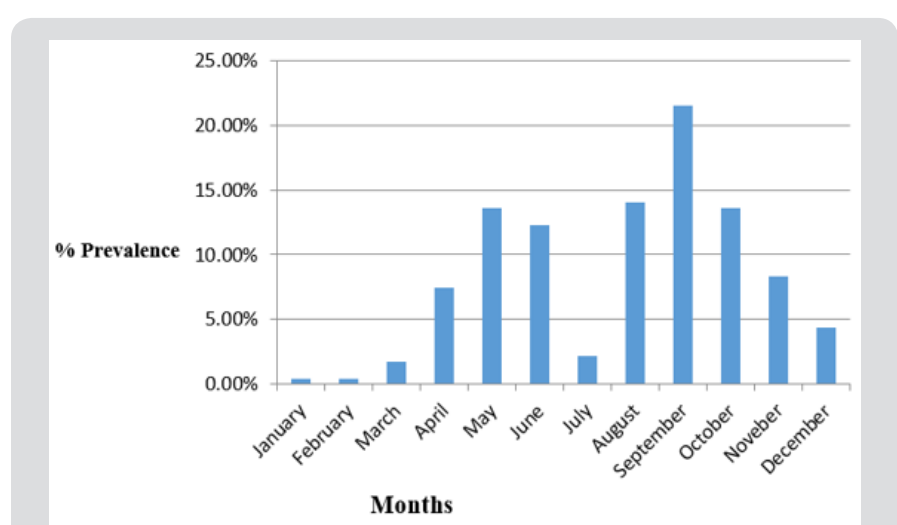

Figure 3: Month wise prevalence of malaria in RHC (Shergarh) Mardan.

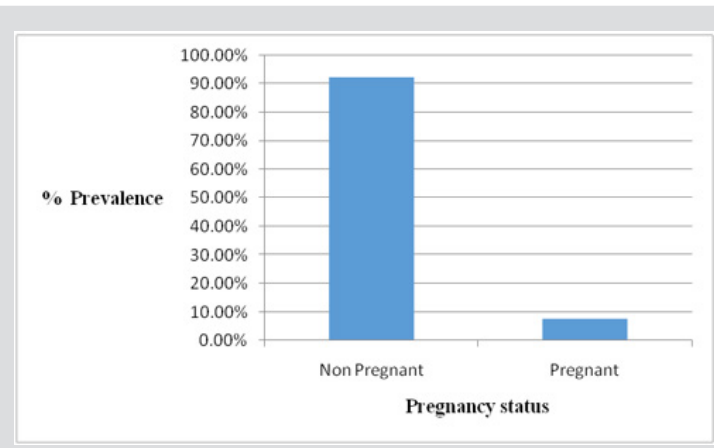

Figure 4: Malaria infection with respect to pregnancy status.

\section{Discussion}

Malaria is considered to be one amongst the leading causes of morbidity and mortality worldwide, particularly in tropical and sub tropical areas of the world. The infecting rate of malaria infection in Pakistani community is concerning one million each year. Malaria is the second most typical illness in West Pakistan that accounts for $16.5 \%$ disease burden rate across the country. Nearly 0.3 million microscopic examined confirmed cases were reportable in 2011 . More than $80 \%$ cases of malaria were contributed by P. vivax and the remaining by P. falciparum [15]. The present study is compared with Kashif Rahim that was conducted in BHU Gala Der District Mardan in which the prevalence rate was $13.9 \%$. The sample size of that study was 782 while the simple size in present study is 2830 .
In present study the prevalence rate is low as compared to other study that was conducted in District Mardan. It is difficult to predict trends of malaria incidence in Pakistan, because of fluctuation of malaria confirmed cases on yearly basis [16].

Another study conducted in Lal Qila, Lower Dir, revealed $29 \%$ malaria incidence [17] while 27\% in Bannu [18] and about $33 \%$ in Barkhan and Kohlu districts of Balochistan have also been reported [19]. A study conducted in Abbottabad reported 7\% malaria cases [20], while Buner district had 7\% prevalence [21]. A study conducted on clinical isolates from Sindh province reported about 3\% malaria endemic [21]. Within population variation in prevalence and distribution of plasmodium species might exist, unfortunately, there are no simple methodological explanations for this variability. Variation in malaria prevalence reflects the different dynamic of malaria transmission among different areas of Pakistan [22]. Similarly, a report from Dera Ismail Khan, revealed 95\% of malaria cases were of $P$. vivax, [23] another study reported $96 \%$ P. vivax cases from Manshera [24], 82\% P. vivax cases in Quetta [25] and 72\% cases in Jacobabad [26]. A comprehensive higher population survey on malarial isolates from all over Pakistan reported $P$. vivax predominance by $76 \%$ [27].

The doable reason of high infection is that relapses overtimes occurred in P. vivax not in P. falciparum. The second reason is that $P$. vivax is usually gift in tropical and climatic zone areas [28]. This study shows that there was a considerable connection between malaria infection and gender in the study area as a higher infection rate was observed in males than females. It has been suggested for the disproportionate cases of malaria in male patients might be due to increased contact because males are more expected to work outside furthermore males not be as well covered as females which might be the possible reason for infected Anopheles bites. The malarial infections may also be associated with some degree of complicated sign and symptoms included prostration, any impairment of consciousness, convulsions or any manifestation of shock, decreased urinary output, respiratory distress or abnormal bleeding should be treated with parenteral rather than oral drugs [29].

\section{Conclusion}

This study showed that the prevalence rate of malaria infection is comparatively more in male population with age between 30-45 years. P. vivax is the most prevalent species in the study area. The finding of this study will help in updating the epidemiological profile of malaria in the study area and other surrounding areas with same ecological conditions in Khyber Pakhtunkhwa. Awareness of population and extending better health facilities will help in control of malarial infection in rural areas of Pakistan. 


\section{Acknowledgment}

This study was supported by Higher Education Commission (HEC) of Pakistan under NRPU program project No. NRPU-3474.

\section{References}

1. Lee KS, Divis PC, Zakaria SK, Matusop A, Julin RA, et al. (2011) Plasmodiumknowlesi: reservoir hosts and tracking theemergence in humans and macaques. PLoS Pathog 7: e1002015.

2. Tuteja R (2007) Malaria - an overview. FEBS J 274: 4670-4679.

3. (2017) WHO, World Malaria Report 2017. World Health Organization, Geneva.

4. (2016) WHO, World Malaria Report 2016. World Health Organization, Geneva.

5. Jamieson A, Toovey S, Maurel M (2006) Malaria: J Traveller's Guide. Struik p. 30.

6. Kattenberg JH, Ochodo EA, Boer KR, Schelling HD, Menes PF, et al (2011) Systematic review and meta-analysis: Rapid diagnostic tests versus placental histology, microscopy and PCR for malaria in pregnant women". Malaria J 10: 321.

7. (2008) World Health Organization. World malaria report 2008. World Health Organization.

8. Nkrumah, Bernard (2010) Performance of the Novel Partec Rapid Malaria Test-" in the Diagnosis of Malaria in a Rural Endemic Area; a Quicker, Cheaper and Cost-Effective Alternative?

9. Leslie T, Mohammed N, Omar H, Rasheed HU, Vorst F, et al. (2008) Malaria sentinel surveillance in Afghanistan. Afgh Ann Malar J 3: 114-128.

10. Gething PW, Patil AP, Smith DL, Guerra CA, Elyazar IR, et al. (2011) A new world malaria map: Plasmodium falciparum endemicity in 2010 . Malar J 10: 378

11. (2015) World Health Organization. Global technical strategy for malaria 2016-2030. World Health Organization.

12. Suwonkerd W, Ritthison W, Ngo CT, Tainchum K, Bangs MJ, et al. (2013) Vector biology and malaria transmission inSoutheast Asia. Anopheles mosquitoes GÇönew insights into malaria vectors.

13. Williams 0, Meek S (2011) Malaria: country profiles. London: Department of international development.

14. Kakar Q Khan MA, Bile KM (2010) Malaria control in Pakistan: new tools at hand but challenging epidemiological realities. East Mediterr Health J 16Supply: 54-60.

\section{ISSN: 2574-1241}

DOI: 10.26717/BJSTR.2019.18.003210

Sahib Gul Afridi. Biomed J Sci \& Tech Res

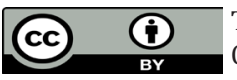

This work is licensed under Creative Commons Attribution 4.0 License

Submission Link: https://biomedres.us/submit-manuscript.php
15. (2017) Directorate of Malaria Control.

16. (2013) World Health Organization. World Malaria Report 2013. Geneva: World Health Organization: Fecha de consulta, 2014.

17. Yasinzai MI, Kakarsulemankhel JK (2009) Prevalence of human malaria infection in bordering areas of East Balochistan, adjoining with Punjab: Loralai and Musakhel. J Pak Med Assoc 59(3): 132-135.

18. Hussain A, Ahmad T, Ullah N, Jadoon MA, Zohaib (2014) Epidemiological Approach to Malaria: Plasmodium vivaxisCommon in LalQilla (Subdivision), Pakistan. World Applied Sci J 30(1): 29-31.

19. Khan SN, Ayaz S, Khan S, Attaullah S, Khan MA, et al. (2013) Malaria: Still a Health Problem in the General Population of BannuDistrict, Khyber Pakhtunkhwa, Pakistan. Ann Rev Res Biol 3(4): 835-845.

20. Yasinzai MI, Kakarsulemankhel JK (2008) Incidence of human malaria infection in bordering areas adjoining with Punjab: Barkhan and Kohlu. Pak J Med Sci 24(2): 306-310.

21. Idris M, Sarwar J, Fareed J (2007) Pattern of malarial infection diagnosed at Ayub Teaching Hospital Abbottabad. J Ayub Med Coll Abbottabad 19(2): 35-36.

22. Murtaza G, Memon IA, Memon AR, Lal MN, Kallar NA (2009) Malaria morbidity in Sindh and the Plasmodium species distribution. Pak J Med Sci 25(4): 646-649.

23. Idris ZM, Chan CW, Kongere J, Gitaka J, Logedi J, et al. (2016) High and Heterogeneous Prevalence of Asymptomatic and Submicroscopic Malaria Infections on Islands in Lake Victoria, Kenya. Sci Rep 6: 36958.

24. Ullah Z, Noor B, Nadeem MF, Hayyat A, Khattak AA (2015) Evaluation of immunochromatographic (ICT) assay and microscopy for malariadiagnosis in endemic district Dera Ismail Khan. Inter J Bio Sci 6(8): $37-42$

25. Jalal UD, Khan SA, Ally SH (2006) Malaria in children: study of 160 cases at a private clinic in Mansehra. J Ayub Med Coll Abbottabad 18(3): 44-45.

26. Soomro FR, Pathan GM, Bajaj D, Kakar JK (2010) Malarial parasites species; Jacobabad District Sindh, Pakistan. Prof Med J 17(3): 440-443.

27. Khattak AA, Venkatesan M, Nadeem MF, Satti HS, Yaqoob A, et al. (2013) Prevalence and distribution of human Plasmodium infection in Pakistan. Malar J 12: 297.

28. Suleman M, Zia ur Rahman Awan, Hafiz Tayyeb Ali Shah, Abdul Haleem Shah, Murad Ali Khan (2012) Malaria Among the Students of Religious Schools of Bannu District, Khyber Pakhtunkhwa, Pakistan. Pak J Zool 44: 959-962.

29. Pasvol G (2006) The treatment of complicated and severe malaria. $\mathrm{Br}$ Med Bull 25: 75-76.

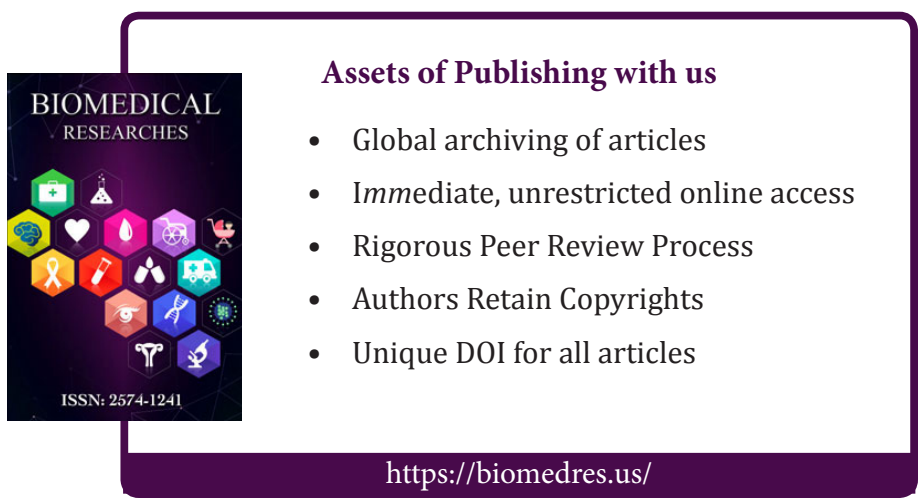

